\title{
Musculature of the male genitalia in Rivellia (Diptera: Platystomatidae)
}

\author{
Tatiana V. Galinskaya', Olga G. Ovtshinnikova² \\ I Department of Entomology, Faculty of Biology, Lomonosov Moscow State University, Leninskie Gory 1-12, \\ Moscow, 119234, Russia 2 Zoological Institute, Russian Academy of Sciences, St. Petersburg, 199034, Russia \\ Corresponding author: Tatiana V. Galinskaya (nuha1313@gmail.com)
}

Academic editor: M. Hauser $\mid$ Received 28 September 2015 | Accepted 17 November 2015 | Published 14 December 2015

http://zoobank.org/535FF7DE-0272-4DA3-9121-5B06ED1AD016

Citation: Galinskaya TV, Ovtshinnikova OG (2015) Musculature of the male genitalia in Rivellia (Diptera: Platystomatidae). ZooKeys 545: 149-158. doi: 10.3897/zookeys.545.6702

\begin{abstract}
The musculature of male genitalia was studied hitherto only in two species of Tephritidae, one species of Platystomatidae, one species of Pallopteridae, and three species of Ulidiidae of the superfamily Tephritoidea. The split of the hypandrium from one structure into three (the hypandrium and two lateral sclerites) is traced. The hypandrial origin of the lateral sclerites of the hypandrial complex is shown based on the localization of muscle attachment sites. The subepandrial origin of the inner lobes of the surstyli is also confirmed.
\end{abstract}

\section{Keywords}

Tephritoidea, Platystomatidae, male genitalia, sclerites, musculature, body size

\section{Introduction}

The signal flies (Tephritoidea: Platystomatidae) include nearly 1300 described species of more than 120 genera occurring predominantly in the Paleotropics, with a few genera and species in the Holarctic and Neotropic regions (V.A.Korneyev, unpublished 
data). They are a sister group to the Pyrgotidae + Tephritidae lineage, sharing with them numerous synapomorphies, including the structures of male genitalia, such as the phallus stored in rest in a membranous pocket under the $5^{\text {th }}$ tergite of abdomen, glans clearly separated from the remaining part of distiphallus, lateral (outer) surstyli fused to epandrium, phallapodeme and adjusting structures of hypandrium forming a "fultella", etc. (Korneyev 1999).

The male postabdomen in Platystomatidae consists of modified segments 6-8 (pregenutal segments) and derivatives of segments 9-11 forming the genitalia and cerci. In the superfamily Tephritoidea, the musculature of the male genitalia has been studied in representatives, shown in Table 1.

Table I. Representatives of the superfamily Tephritoidea, in which the musculature of the male genitalia has been studied.

\begin{tabular}{lll}
\hline \multicolumn{1}{c}{ Species } & \multicolumn{1}{c}{ Family } & \multicolumn{1}{c}{ Reference } \\
\hline Ceratitis capitata (Wiedemann, 1824) & Tephritidae & $\begin{array}{l}\text { Hanna (1938), Valdez-Carrasco and } \\
\text { Prado-Beltran (1990) }\end{array}$ \\
\hline Campiglossa hirayamae (Matsumura, 1916) & Tephritidae & Sueyoshi (2006) \\
\hline Rivellia basilaris (Wiedemann, 1830) & Platystomatidae & Sueyoshi (2006) \\
\hline Temnosira trichaeta Ozerov, 1993 & Pallopteridae & Sueyoshi (2006) \\
\hline Timia erythrocephala Wiedemann, 1824 & Ulidiidae & Galinskaya and Ovtshinnikova (2015) \\
\hline Ulidia ruficeps Becker, 1913 & Ulidiidae & Galinskaya and Ovtshinnikova (2015) \\
\hline Physiphora alceae (Preyssler, 1791) & Ulidiidae & Galinskaya and Ovtshinnikova (2015) \\
\hline
\end{tabular}

There are different views on the homology of some genital sclerites in the superfamily Tephritoidea. Different terminology is therefore used for some structures in a few cases, where morphology of Platystomatidae genitalia is considered: outer and inner surstyli (McAlpine 1973, 1999) or lateral and medial surstyli (White et al. 1999, Korneyev 2001); lateral sclerites of hypandrium (McAlpine 1973, White et al. 1999), gonites and vanes of fultella (Korneyev 1987), gonocoxites and vanes of phallapodeme (Korneyev 1999); decasternum or $10^{\text {th }}$ sternite (Korneyev 1987), ventral plate of proctiger, derivate of $10^{\text {th }}$ sternum (Ovtshinnikova 1989, 1994, 2000), subepandrial sclerite (Cumming et al. 1995) etc. Here, we provisionally follow terminology of White et al. (1999), with some reservations.

Study of the musculature is helpful not only in specifying the functions of genital sclerites, but also for revealing homology of some poorly traced structures (Ovtshinnikova 1989, 1993, Ovtshinnikova and Yeates 1998; Galinskaya and Ovtshinnikova 2015). Recently, the musculature of the male genitalia was described for three species of the tribe Ulidiini (Galinskaya and Ovtshinnikova 2015) of the family Ulidiidae, which is a basal group to Platystomatidae + Pyrgotidae + Tephritidae lineage (Korneyev 1999).

In this paper, the musculature of male genitalia is described in Rivellia (Platystomatidae), continuing comparative study of morphology of the Tephritoidea. 


\section{Methods}

The terminology of the genital sclerites mainly follows White et al. (1999), Kameneva (2000), Galinskaya (2012), and Sinclair (2000).

Musculature of the male genitalia was studied by manually dissecting material (preserved fresh in 70\% alcohol) with microknives in water under a Leica MZ95 stereomicroscope. The illustrations were obtained using the image capture function of the Leica MZ9 ${ }^{5}$ trinocular head and subsequently processed.

The male genital muscles of Tephritoidea were classified into several groups: muscles of the epandrial complex, muscles of the hypandrial complex, tergosternal muscles, and pregenital muscles. The muscles are designated by numbers following the classification previously accepted by Ovtshinnikova (1989).

List of abbreviations: cerc - cerci; epand - epandrium; bph - basiphallus; hypd hypandrium; $\mathbf{1}$ scl - lateral sclerite of hypandrium; $\mathbf{l}$ sur - lateral surstylus; m sur median surstylus; phapod - phallapodeme; sbepand scl - subepandrial sclerite; sec scl - secondary sclerotisation of hypandrial membrane; sur - surstylus; 8 stgst -8 syntergosternite; M1-M19 - muscles.

\section{Results}

\section{Platystomatidae}

\section{General plan of male genitalia}

Male genitalia are similar to those in Tephritidae: hypandrium U-shaped, with membranous fold posterior of basiphallus, but without epiphallus, metaphallic plate, or a sclerotized bridge connecting posteromedial cornu of hypandrium; phallapodeme firmly fused to paired sclerotized bars, forming V- or Y-shaped "fultella" (term of Griffiths 1972), flexibly joined to the paired bar-like sclerites called "lateral sclerites of hypandrium" (McAlpine 1973) posteriorly fused to hypandrium and laterally connected to hypandrium by membrane; they are sometimes considered to be walls of modified, rudimentary gonites (Korneyev 1987) or gonocoxites (Korneyev 1999); in Rivellia, the left sclerite is completely fused with hypandrium (Korneyev 1985, Sueyoshi 2006), whereas in genera related to Platystoma, and in a few examined Scholastinae and Plastotephritinae both sclerites are symmetrical and free anteriorly (Korneyev 1985, 2001, Whittington 2003) membranous bottom of hypandrium allied to basiphallus in most "Higher Tephritoidea," including Platystomatidae usually with a pair of small rounded sclerites (bearing fields of 8 trichoid mechanoreceptive sensilla), sometimes considered to be rudiments of parameres (Korneyev 1987) or gonopodites (Korneyev 1999). Epandrium dorsally setose, with lateral (or outer) surstyli fused to it without a seam, and connected either anteroventrally (Scholastinae, Plastotephritinae, Rivellia and related genera - see McAlpine 1973, Korneyev 1985, Hara 1989, Whittington 2003, Sueyoshi 2006, Galinskaya and Shatalkin 2013) or posteroventrally (Platystoma 
and related genera - see Hara 1987, Korneyev 2001). Ventrally of epandrium, a V-, $\mathrm{X}$-, or H-like sclerite, the subepandrial sclerite (Cumming et al. 1995), sometimes referred as $10^{\text {th }}$ sternite or decasternum (e.g., Korneyev 1987) or, in its medial part, as "plate-like", "transverse" or "bacilliform sclerite" (Sueyoshi 2006) is located between the hypandrium and cerci; Ovtshinnikova $(1989,1994)$ considered this sclerite to be a possible derivative of $10^{\text {th }}$ sternum and Cumming et al. (1995) considered this sclerite to be a possible derivative of sclerotized intersegmental membrane of the $10^{\text {th }}$ sternum. Its posterolateral lobes often form a pair of finger-like projections, called medial (inner) surstyli, bearing setae, including pair or subapical, dentate, thickened prensisetae; in Scholastinae and Plastotephritinae inner surstylus usually short, with prensisetae basal, whereas in most Platystomatinae, including Platystoma, Rivellia and related genera, the prenisetae are subapical, closer to apex of lateral surstylus (McAlpine 1973, Hara 1989, Korneyev 2001). Phallus consists of a basal ring-like, sclerotized basiphallus, flexibly joined to paired posterior arms of the phallapodeme, and a long tubular and coiled distiphallus, apically bearing a clearly expressed glans, well separated by a fold. Cerci usually large and apically widened (see McAlpine 1973, Korneyev 2001, Galinskaya and Shatalkin 2013) ${ }^{1}$.

\section{Musculature of the male genitalia}

\section{Rivellia alini Enderlein, 1937}

Material. 3 males: Russia, Primorsky Krai, Ussuri District, Kamenushka, 4 August 2013 (T.V. Galinskaya).

Description. Lateral sclerite of hypandrium separated from hypandrium at right side; left sclerite completely fused with hypandrium. Subepandrial sclerite consisting of the elongate bifurcated medial part and elongate postero-lateral lobes. Lateral surstylus long, apically curved. Cerci paired, long, sclerotized, ventrally connected to subepandrial sclerite (Figure 1).

Platystomatidae have same set of muscles as in Ulidiidae, differing from them by the degree of development, shape, and their attachment sites (Figures 2, 3).

Muscles of the hypandrial complex: $M 1, M 2$, and M23. Strong, wide, and short phallapodeme retractors $M 1$ connect the anterior part of hypandrium with grooves on the Y-shaped phallapodeme arms. Strong, wide, and long phallapodeme protractors M2 are attached to the distal half of the lateral surfaces of the unpaired phallapodeme lobe and to the inner surface of hypandrium at left and to the lateral sclerite at right side.

Ejaculator compressors M23 strong and long, surrounding ejaculator apodeme. Their contraction pumps semen into the phallus.

Tergosternal muscles. Tergosternal muscles $M 5$ long, fan-shaped, connecting lateral parts of the epandrium anterior margin with lateral parts of anterior margin of

1 The short characteristic of genital structures was kindly compiled by Valery A. Korneyev. 
a)
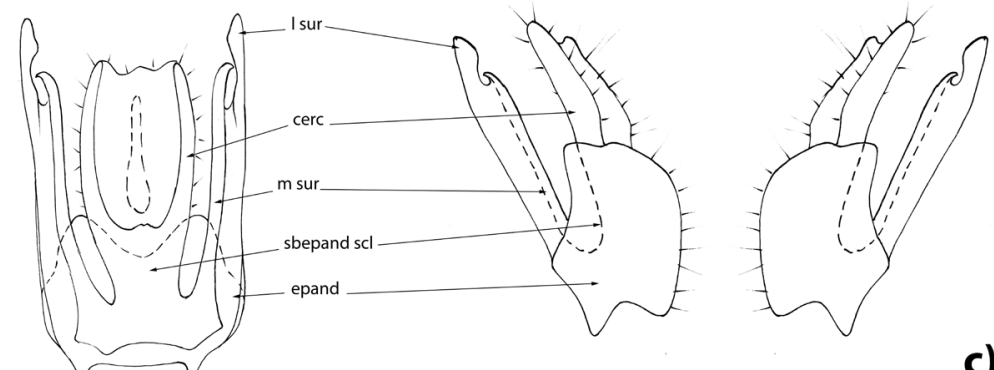

b)
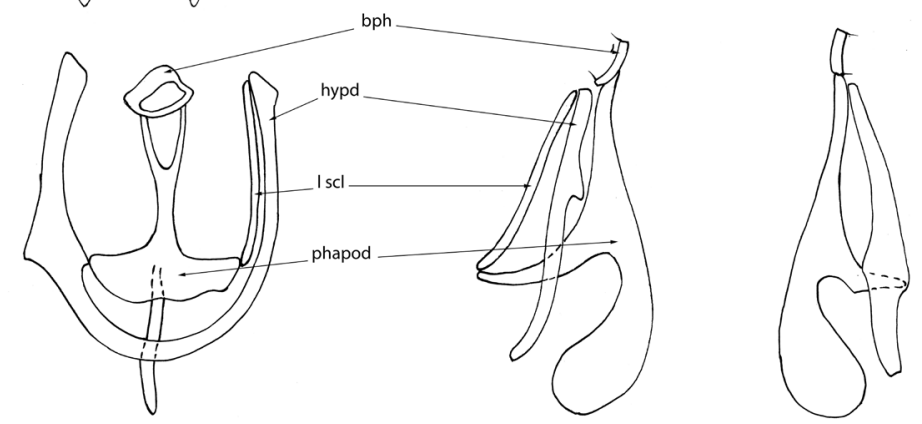

c)

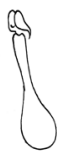

Figure I. Male genitalia of Rivellia alini Enderlein, 1937. a epandrium in ventral, right lateral and left lateral views $\mathbf{b}$ hypandrium in dorsal, right lateral and left lateral views $\mathbf{c}$ ejaculatory apodeme.

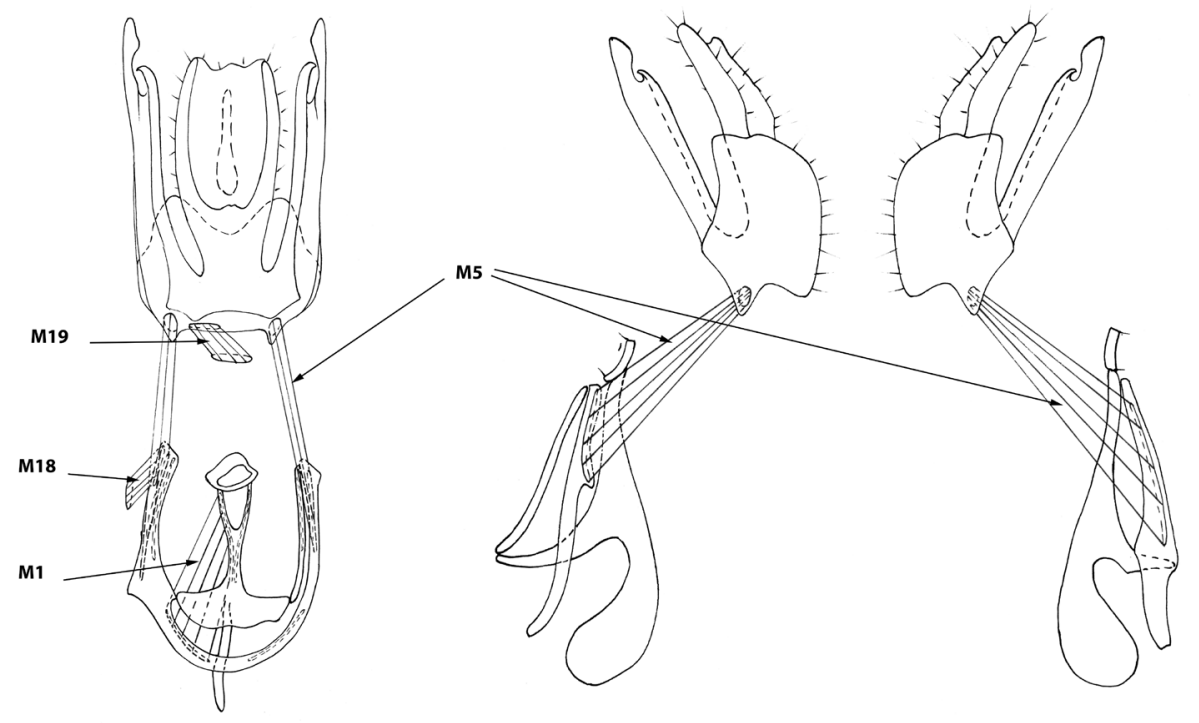

Figure 2. Male genitalia of Rivellia alini Enderlein, 1937. Epandrium and hypandrium in inner, right lateral and left lateral views. 
a)

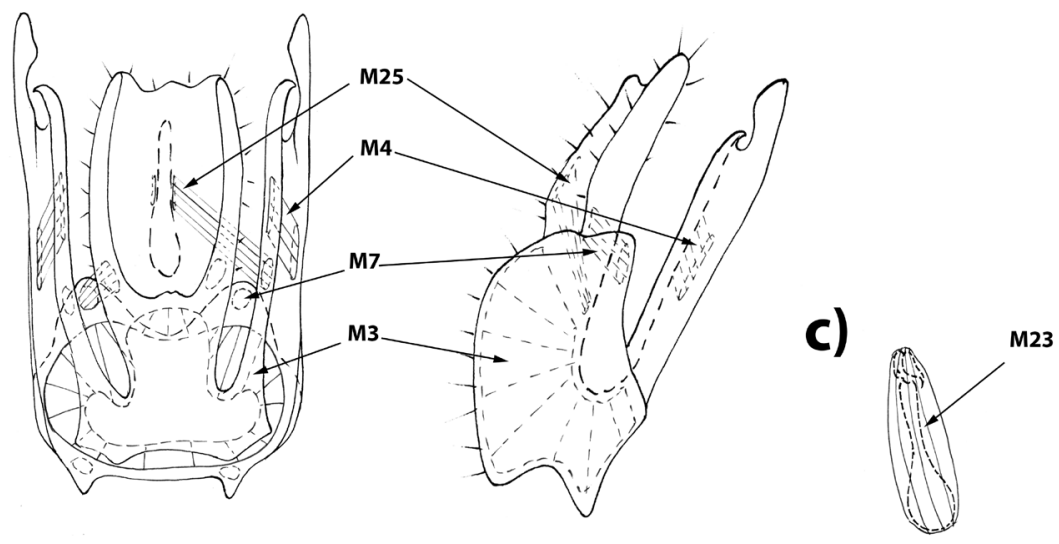

\section{b)}

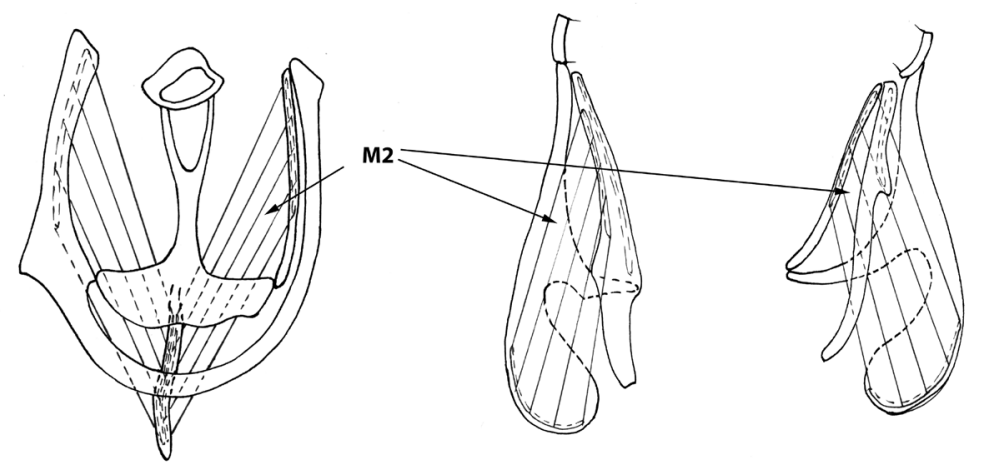

Figure 3. Male genitalia of Rivellia alini Enderlein, 1937. a epandrium in ventral and left lateral views b hypandrium in dorsal, left lateral and right lateral views $\mathbf{c}$ ejaculatory apodeme.

hypandrium (in contrast to Ulidiidae, in which these muscles are attached to the distal margin of the hypandrium). These muscles draw hypandrium to epandrium. During copulation, epandrium clasps female's ovipositor while the hypandrium is retracted into the male's abdomen by contraction of these muscles.

Muscles of the epandrial complex: M3, M4, M7, and $M 25$.

Subepandrial sclerite adductors $M 3$ strong, connecting the inner surface of the epandrium (occupying a considerable part of it) to the inner surface of anterior part of the subepandrial sclerite as a wide bundle.

Adductors of surstyli $M 4$ short, fine, poorly visible, extending from the middle of long posterolateral lobe of the subepandrial sclerite (medial surstyli) to the middle of lateral part of at inner surface of the (lateral) surstylus. 
Cercus retractors $M 7$ short, fine, extending from the inner surface of the basal part of the epandrium to the basal cercal lobes.

The long and fine poorly visible retractors of anal integument M25 connect the median part of medial surstyli with the basal part of the rectum.

Pregenital muscles: $M 18^{2}$ and $M 19$. The unpaired adductor of the hypandrium $M 18^{2}$ extends from the distal part of syntergosternite 8 to the left hypandrial arm. The strong fan-shaped unpaired epandrial retractor $M 19$ obliquely extends from the distal part of syntergosternite 8 to the left part of the basal margin of the epandrium.

\section{Discussion and Conclusions}

Our results were compared with musculature of male genitalia of Rivellia basilaris (Wiedemann, 1830) studied by Sueyoshi (2006). In this species he studied muscles of epandrial complex and tergosternal muscles and revealed three pair of muscles: M42+43 (=M4 sensu Ovtshinnikova), M31 (=M3), M34 (=M5). We confirmed his results and expanded the area of the study.

Comparisons of descriptions revealed homologies and the following correspondence between numbers of homologous muscles (Galinskaya and Ovtshinnikova 2014) (Table 2).

Table 2. Homologous muscles of Tephritoidea from different articles.

\begin{tabular}{lll}
\hline $\begin{array}{l}\text { Number of muscle } \\
\text { in current research }\end{array}$ & \multicolumn{1}{c}{ Numbers of homologous muscles } & Muscle complex \\
\hline$M 1$ & MUS1 (Hanna 1938) and M41 (Sueyoshi 2006) & Hypandrial complex \\
\hline$M 2$ & MUS2 (Hanna 1938) and M35-37 (Sueyoshi 2006) & Hypandrial complex \\
\hline$M 23$ & MUS (Hanna 1938) & Hypandrial complex \\
\hline$M 5$ & $M 34$ (Sueyoshi 2006) & Tergosternal complex \\
\hline$M 3$ & $M 31$ (Sueyoshi 2006) & Epandrial complex \\
\hline$M 4$ & $M 42+43$ and M44(Sueyoshi 2006) & Epandrial complex \\
\hline$M 7$ & $M C$ (Sueyoshi 2006) & Epandrial complex \\
\hline
\end{tabular}

Analysis of the attachment sites of muscles has shown that in all studied families paired phallapodeme muscles $M 2$ are attached with one end to the distal half of the lateral surface of the unpaired lobe of phallapodeme, and with the other end it is attached either to the the inner surface of the hypandrial arms (in Ulidiidae; only on the left side, in Rivellia ); they are attached to the lateral sclerites in some Tephritidae and (only on the right side) in Rivellia. Thus, the attachment of $M 2$ muscles to the lateral sclerites confirms their hypandrial origin.

It can be noted that the attachment sites of the subepandrial sclerite adductors $M 3$ and surstyli adductors $M 4$ are constant and these muscles are thus clearly distinguished 
from each other. These muscles are synergistic, and when they contract during copulation, the surstyli grasp and hold the female ovipositor, as they do in most other cyclorrhaphan flies, including those considerably different in the structure of the surstyli and subepandrial sclerite.

Comparative analysis shows that studied Rivellia displays similar sets of muscles of the male genitalia, close to the plan of structure fundamental for Cyclorrhapha, possibly as a result of reduction of or lacking some of the muscles (Ovtshinnikova 1989), and differs from this fundamental plan in the split of muscle $M 3-4$ into two pairs and presence of muscles of the anal integument $M 25$, which is also typical of the family Syrphidae. We have also noted asymmetry in the muscles of genitalia.

In this paper we confirmed the hypandrial origin of lateral sclerite and or medial surstylus is a lobe derived from the bacilliform sclerite.

\section{Acknowledgements}

For useful criticism and many interesting discussions we are grateful to A.I. Shatalkin (ZMMU). We thank P.N. Petrov (Department of Entomology, Faculty of Biology, Lomonosov Moscow State University) for improuving the English of the manuscript. Authors are very grateful to V.A.Korneyev for reviewing, greatly improuving the manuscript and many valuable comments. Authors are also grateful to B. Sinclair for reviewing the manuscript.

The work of T.V. Galinskaya was financially supported by the Russian Science Foundation (14-14-00208); that of O.G. Ovtshinnikova, was performed in the scopes of the state research project No. 01201351183 and by the Russian Foundation for Basic Research, project No. 15-04-03457.

\section{References}

Cumming JM, Sinclair BJ, Wood DM (1995) Homology and phylogenetic implications of male genitalia in Diptera - Eremoneura. Entomologica Scandinavica 26: 120-151. doi: $10.1163 / 187631295 \times 00143$

Galinskaya TV (2011a) Review of the yellow-bodied species of the genus Timia (Diptera: Ulidiidae) with description of two new species. Zootaxa 2888: 1-22.

Galinskaya TV (2011b) A new species of Ulidia (Diptera: Ulidiidae) from Turkmenistan and Uzbekistan. Zoosystematica Rossica 20(1): 153-158.

Galinskaya TV (2012) Palaearctic Ulidiidae (Diptera): systematic, morphology, phylogeny and area of distribution. PhD thesis, MSU, Moscow.

Galinskaya TV (2014) Two new species of the genus Timia (Diptera: Ulidiidae) with a key to species with microtrichose black scutellum. Zootaxa 3753(6): 573-584. doi: 10.11646/ zootaxa.3753.6.4 
Galinskaya TV, Ovtshinnikova OG (2015) Musculature of the male genitalia in the tribe Ulidiini (Diptera, Ulidiidae). Entomological Review 95(1): 31-37. doi: 10.1134/ S0013873815010042

Galinskaya TV, Shatalkin AI (2013) Neohemigaster Malloch, 1939 and Pterogenia Bigot, 1859 (Diptera: Platystomatidae) from eastern Eurasia, with the description of four new species. Zootaxa 3666(2): 267-285. doi: 10.11646/zootaxa.3666.2.9

Hanna AD (1938) Studies on the Mediterranean Fruit-Fly: Ceratitis capitata Wied. 1. The Structure and Operation of the Reproductive Organs. Bulletin de la Societe entomologique d'Egypte 22: 39-59.

Kameneva EP (2000) Picture-winged flies (Diptera, Ulidiidae) of Palearctics (fauna, morphology \& systematics). PhD thesis, I.I. Schmalhausen Institute of Zoology, National Academy of Sciences of Ukraine, Kiev. [In Ukrainian, manuscript]

Korneyev VA (1985) Tephritid flies (Diptera, Tephritidae) of the Middle Dnieper Territory (with a review of classifications of the family worldwide). PhD thesis, T.G.Shevchenko State University of Kiev, Kiev, 469 pp. [In Russian, manuscript]

Korneyev VA (1987) The analysis of comparative morphology of the male terminalia in acalyptrate Diptera of the tephritoid complex. In: Nartshuk EP (Ed.) Two-winged insects: systematics, morphology and ecology. [Proc. of the 4th All-Union Dipterological Symposium, Alma-Ata, Sept. 17-19, 1986]. Zoological Institute, Leningrad, 49-56. [In Russian]

Korneyev VA (1999) Phylogenetic relationships among higher groups of the superfamily Tephritoidea. In: Norrbom AL, Aluja M (Eds) Fruit flies (Diptera: Tephritidae): Phylogeny and Evolution of Behavior. Proc. of Symposium, Xalapa, Veracruz, Mexico, February 16-21, 1998. CRC Press, Boca Raton, 3-22.

Korneyev VA (2001) A key to genera of Palaearctic Platystomatidae (Diptera), with descriptions of a new genus and new species. Entomological Problems (Bratislava) 32(1): 1-16.

McAlpine JF (1981) Morphology and terminology - Adults. 2. In: McAlpine JF (Ed.) Manual of Nearctic Diptera, vol 1. Research Branch Agric, Canada, Ottawa, 9-64.

McAlpine JF (1989) Phylogeny and classification of the Muscomorpha. In: McAlpine JF (Ed.) Manual of Nearctic Diptera, vol 3. Research Branch Agric, Canada, Ottawa, 1397-1518.

McAlpine DK, Kim SP (1977) The Genus Lenophila (Diptera: Platystomatidae). Records of the Australian Museum 30(13): 309-336. doi: 10.3853/j.0067-1975.30.1977.391

Ovtshinnikova OG (1989) Muscles of the male genitalia of Brachycera-Orthorrhapha (Diptera). Trudy Zool. Inst. Akad. Nauk, SSSR 190: 1-166.

Ovtshinnikova OG (1994) On the homology of male genital sclerites of Brachycera Orthorrhapha and Cyclorrhapha (Diptera) based on musculature. Dipterological Research 5(4): 263-269.

Ovtshinnikova OG, Yeates DK (1998) Male genital musculature of Therevidae and Scenopinidae (Diptera: Asiloidea): structure, homology and phylogenetic implications. Australian Journal of Entomology 37(1): 27-33. doi: 10.1111/j.1440-6055.1998.tb01539.x

Ovtshinnikova OG (2000) Muscles of the Male Genitalia of Hover Flies of the Family Syrphidae (Diptera), in N.A. Kholodkovsky Memorial Lectures: a Report at the 52nd Annual Meeting, April 1, 1999 (St. Petersburg, 2000), 70 pp. [In Russian] 
Shatalkin AI (2012) Homologies in the male genital morphology of Cyclorrhapha (Diptera). Caucasian Entomological Bulletin 8(2): 321-327.

Sinclair BJ (2000) 1.2. Morphology and terminology of Diptera male terminalia. In: Papp L, Darvas B (Eds) Contributions to a manual of Palaearctic Diptera. vol 1. Science Herald, Budapest, 53-74.

Sueyoshi M (2006) Comparative morphology of the male terminalia of Tephritidae and other Cyclorrhapha. Israel Journal of Entomology 35: 477-496.

Valdez-Carrasco J, Prado-Beltran E (1990) Esqueleto y musculatura de la Mosca del Mediterraneo Ceratitis capitata (Wiedemann) (Diptera: Tephritidae). Folia Entomologica Mexicana 80: 59-225.

Weinberg M (2003) Data regarding the abdomen and the taxonomical value of genitalia in both sexes of Platystomatidae (Diptera). Travaux du Museum National d'Histoire Naturelle "Grigore Antipa" 45: 279-289.

White IM, Headrick DM, Norrbom AL, Carroll LE (1999) Glossary. In: Aluja M, Norrbom AL (Eds) Fruit Flies (Tephritidae): Phylogeny and Evolution of Behavior. CRC Press, Boca Raton, 881-924. doi: 10.1201/9781420074468.sec8

Whittington AE (2003) Taxonomic revision of the Afrotropical Plastotephritinae (Diptera, Platystomatidae). Studia Dipterologica - Supplement 12: 1-300. 